\title{
Comparison of noninvasive prenatal testing of cell-free DNA in maternal blood and amniocentesis for evaluation of aneuploidy
}

\author{
Meisam Akhlaghdoust ${ }^{1}, \underline{\text { Shahla } \text { Chaichian }^{2}}$ \\ ${ }^{1}$ General Practitioner, Pars Advanced and Minimally Invasive Medical Manners Research Center, Pars Hospital, Iran \\ University of Medical Sciences, Tehran, Iran \\ ${ }^{2}$ Professor, Gynecologist, Minimally Invasive Techniques Research Center in Women, Islamic Azad University Tehran \\ Medical Branch, Tehran
}

\begin{abstract}
Background: The aim of this study was to compare noninvasive prenatal testing (NIPT) of cell-free DNA in maternal blood and amniocentesis in the diagnosis of aneuploidy. This study was designed to evaluate sensitivity, specificity, accuracy, positive predictive value and negative predictive value of NIPT for detection of aneuploidies compared gold standard test of amniocentesis.

Materials and methods: This cross sectional study performed on Iranian pregnant women (GA $\geq 12$ weeks) and candidate for NIPT, referred to the Nilou laboratory in Tehran and 16 provinces of Iran between Aug 2016 and Aug 2018. Analysis study was performed by SPSS version 21.

Results: 11960 pregnant women which candidate for NIPT enrolled in this study and 139 persons detected as high risk for NIPT. The mean ( \pm standard deviation) age of participants was $33.7 \pm 6.4$ years and $34.4 \pm$ 5.2 years for amniocentesis and NIPT groups, respectively. Specificity of NIPT in the diagnosis of trisomies of T21, T18 and T13 was 99.94\%, 99.95\% and 99.97\% respectively. Failure rate was calculated as 0.27 .

Conclusion: Non-invasive prenatal testing has very high sensitivity and specificity for aneuploidies but should not be used as a final diagnosis test.

Keywords: Amniocentesis, NIPT, Cell-free fetal DNA, Aneuploidies.

Cited as: Akhlaghdoust M, Chaichian Sh. Comparison of noninvasive prenatal testing of cell-free DNA in maternal blood and amniocentesis for evaluation of Aneuploidy. Medical Science Journal of Islamic Azad University, Tehran Medical Branch 2020; 30(1): 75-81.
\end{abstract}

Correspondence to: Shahla Chaichian

Tel: +9809121303526

E-mail: shchaichian@iautmu.ac.ir

ORCID ID: 0000-0001-5772-8711

Received: 14 May 2019; Accepted: 2 Jul 2019 
مجله علوم يزشكى دانشگاه آزاد اسلامى

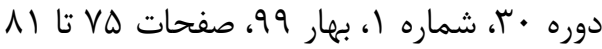

Original

Article

\section{مقايسه روش غيرتهاجمى يافتن DNA آزاد جنينى در یِلاسماى مادرى با روش استاندارد آمنيوسنتز در تشخيص بيش از تولد آنويلوئيدى}

\section{ميثم اخلاق دوست'، شهرلا جايجيان}

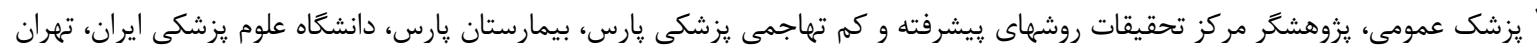

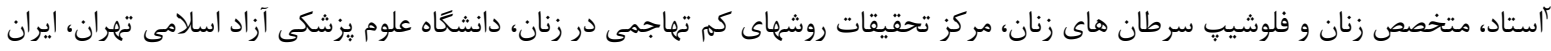

سابقه و هدف: هدف /ز مطالعه حاضر، مقايسه روش غيرتهاجمى يافتن /سيد نوكلئيك آزاد جنينى در بلاسماى مادرى(NIPT) با روش

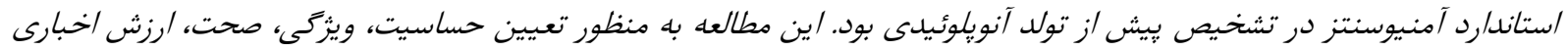

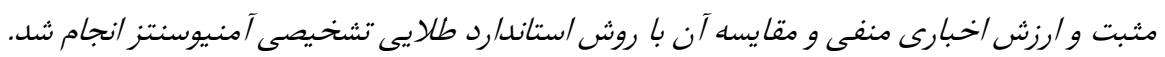

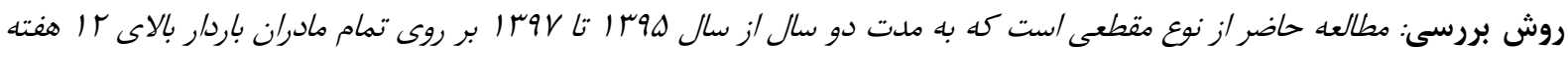

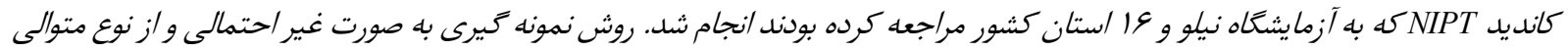

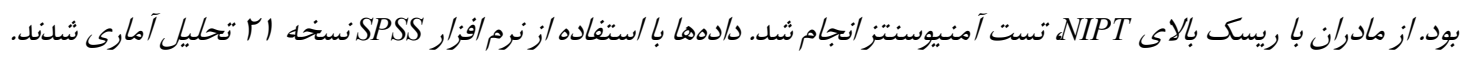

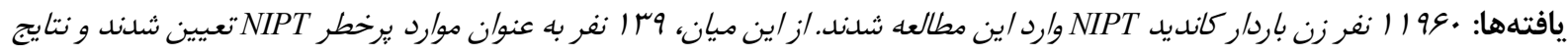

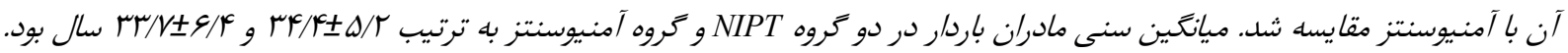

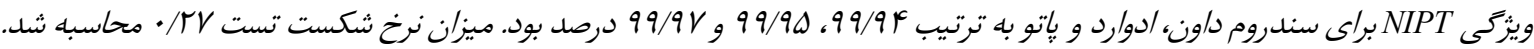

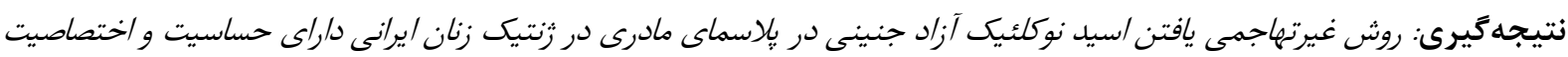

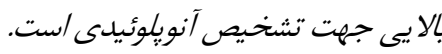

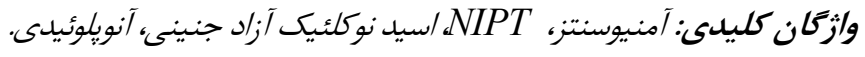

1). از طرف ديكر اغلب زنان بـاردار از ايـن روش بـيم و هـراس

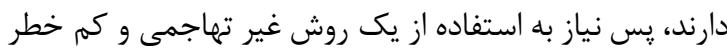
احساس مىشد (r). روش غيرتهاجمى DNA آزاد موجود در گردش خون مادرى باء

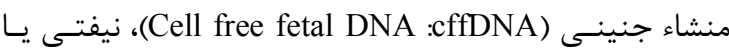
Dennis Lo توسط (non-invasive prenatal testing) NIPT

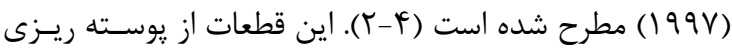

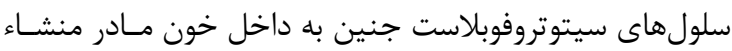

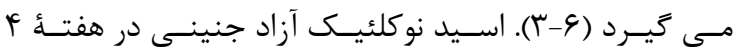

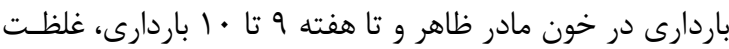

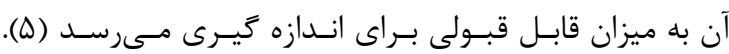

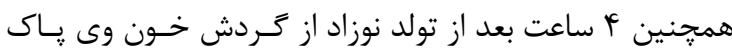

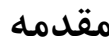

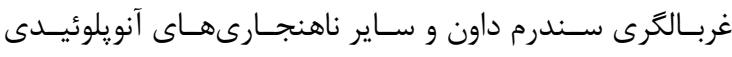

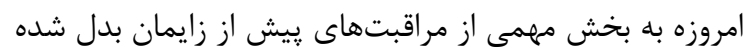

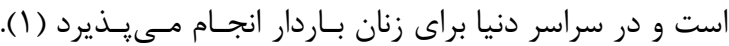

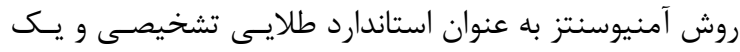

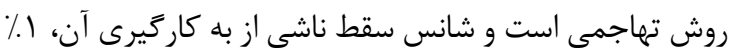

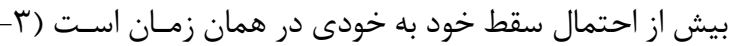

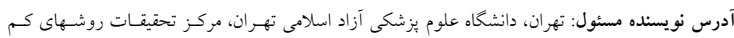

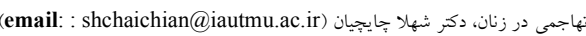
ORCID ID: 0000-0001-5772-8711 تاريخ دريافت مقاله:

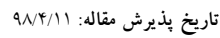


تمام افراد وارد شده به مطالعه بــه قصـد اطـلاع از وجـود بيمـارى تريزومى در نوزاد تا زمان زايمـان و تشـخيص قطعى سـلامت يـا

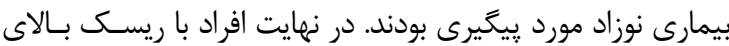
NIPT با استفاده از فرمولهـاى مربـوط بـه تعيـين حساسـيت، ويزگَىى،

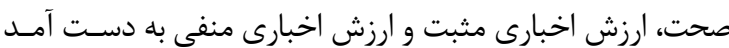

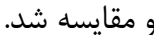

معيارهاى ورود به مطالعه حاضـر شـامل سـن بـاردارى T| هفتـه،

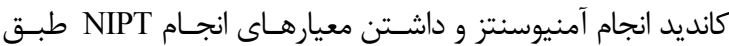
كايدلاين مشـترك متخصصـين زنـان و زايمـان آمريكـا (ACOG: The American College of Obstetricians and The :SMFM) و انجمـن طـب مـادر و جنـين (Gynecologists (Society for Maternal-Fetal Medicine (ه). همجنين معيارهاى خروج از مطالعه شامل يايان باردارى قبـل

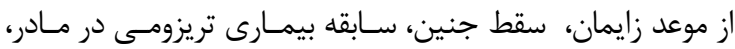
بدخيمى هاى مـادر، وجـود اخـتلالات سـاختارى در سـونوگر افىى، باردارى بيش از دوقلـويى، Nuchal Translucency) NT) بـالاى ؟

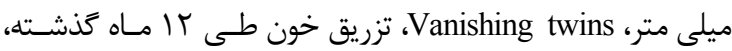
ييوند مغز استخوان، موزائيسم واقعى جنينى و زنان با نمايسه تـوده

بدنى بالاى • r كيلوگرم بر مترمربع بود.

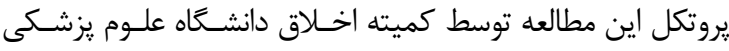

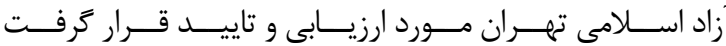

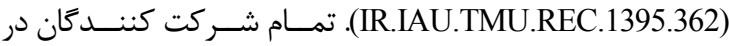
مطالعه يس از توضيحات كامل مراحل تحقيق و با امضاى رضـايت نامه كتبى وارد مطالعه شدند. فرايند انجام NIPT

NIPT تعيين شـده بـراى گـروه يرخطـر در تسـت cut-off ميز

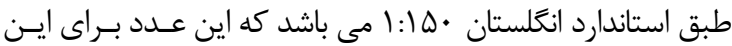

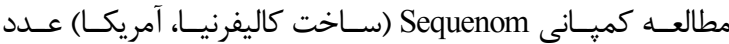

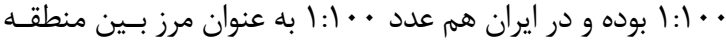
يرخطر و كم خطر براى تست NIPT انتخاب شد. از مـادران يـيش

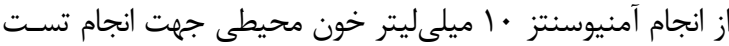

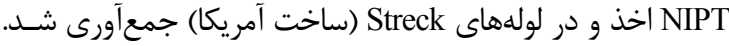
اين لولهها دو مزيت دارند: ا-باعث كاهش ليـز كلبولهـاى سـفيد مىشوند، Y-از نشت اسيد نوكلئيك سلولى به داخل يلاسما قبـل از جداسازى קِلاسما جلوگيرى مى كنـــد. نشـت DNA سـلولى بـــ

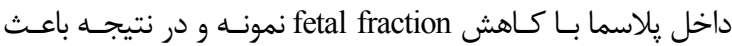
افزايش ميزان شكست (failure rate) نتايج مىشود.
مىشود و قابل تشخيص نيست (V). بنابراين مسىتـوان از ايـن

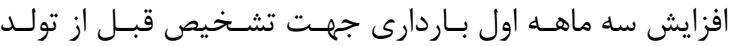

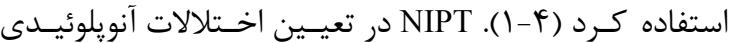
شايع، تشخيص فاكتورهاى مربوط به ناساز كارى سيستم RhD، تعيين جنسيت از نظر اختلالات زنتيكى مـرتبط بـا كرومـوزوم جنسى و تست هاى اختلالات تكى زنسى كـاربرد دارد (V). ايسن تسـت بـراى تشـخيص ناهنجــارىهــاى كرومــوزومى از قبيـل تريزومى ال (سندرم داون) ،تريزومسى \|( ســندرم ادواردز) و تريزومى سا ( سندرم ياتو) كاربرد دارد، ولى تسـت تشخيصى نهايى و جايكزين آمنيوسنتز نيست ( • (1)). عللهاى مختلفى مى توانند منجر به مثبت و منفى كـاذب شـوند و حساسـيت و ويزگ مطالعـات متعـددى ززارشـات متفــاوتى از قـدرت تشـخيص و حساسيت تست ارائه كردهاند و مطالعه جامع و متناسب با نـزّاد

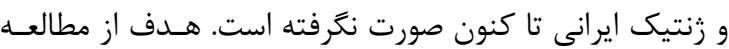
حاضر مقايسه روش غيرتهاجمى يـافتن DNA آزاد جنينسى در

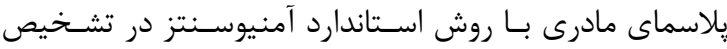

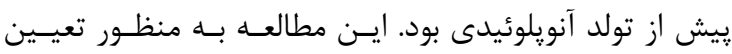

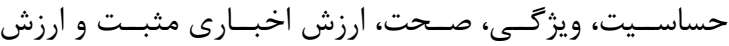
اخبارى منفى و مقايسه آن با روش استاندارد طلايى تشخيصى

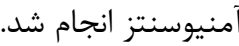

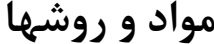 طراحى مطالعه} در اين مطالعه مقطعى، تمام مادران باردار بالاى كا هفتـه كانديـد

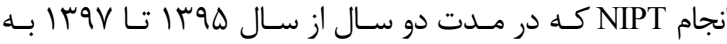
آزمايشعاه تشخيص طبى نيلـو و آزمايشـعاه هــاى طـرف قـرار داد داد

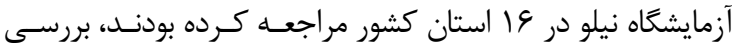
شدند. نمونه گيرى اين تحقيـق بـهـ صـورت غيراحتمـالى و از نــوع

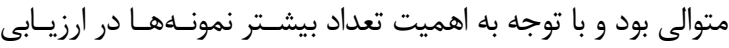

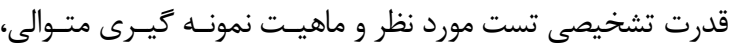
تمام افرادى كه شرايط لازم را داشتند مورد ارزيابى قـرار گرفتنـد. قبل از نمونه گيرى اطلاعات دموگر افيكى و زمينهاى افراد و و سـابقه آنويلوئيدى بيماران اخذ و در يرسشنامه طراحى شده ضـميمه وارد شد. مادران باردار يس از اخذ نمونه خون محيطى به طور مرتـب تحـت

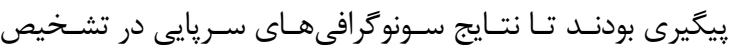
بيمارىهاى احتمالى و نيز جنسيت در اختيار تحقيق قـرار زيـرد. 


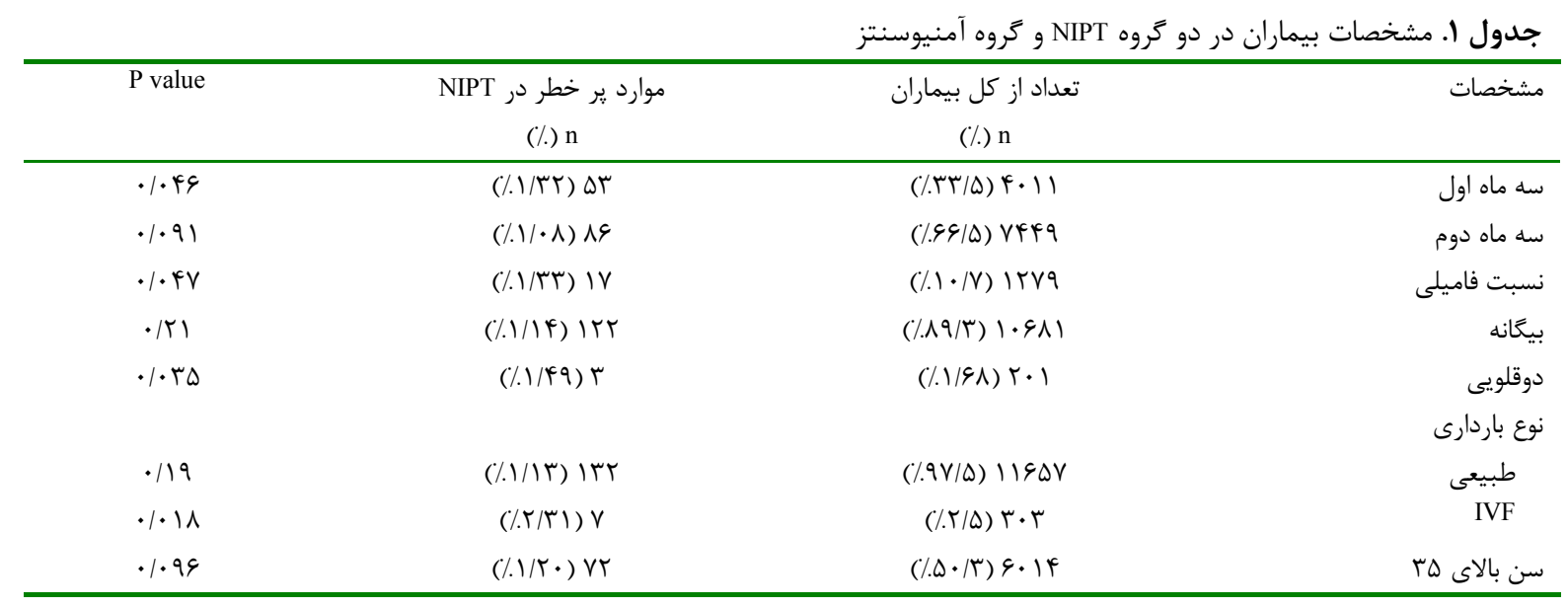

\begin{tabular}{|c|c|c|c|c|}
\hline$P$ value & تعداد ارجاع ير خطر n NIPT) & تعداد ارجاعn (\%) & & نوع اختلال \\
\hline & (\%) & 1199. & & تعداد كل بيماران \\
\hline .1 .11 & $(1.9 / \Lambda \Lambda) \Upsilon \varepsilon$ & $(/ . r / 19)$ rVA & High NT & $\begin{array}{r}\text { Abnormal Ultra } \\
\text { Sound }\end{array}$ \\
\hline.$/ \cdot T V$ & $(/ . / / 4 \Delta) q$ & $(/ . T / 1 \Lambda) Y \varepsilon \mid$ & Hypo plastic or Absent NB & \\
\hline$\cdot / \cdot r F$ & ו & $(/ V / Y \wedge) \wedge \vee I$ & ${ }_{\mathrm{T} 21} \mathbf{H R}^{4.44}$ & FTS* \\
\hline$\cdot / \cdot \Delta$ & $(/ .1 \cdot 19) \mathrm{V}$ & $(\% \cdot \mid \Delta \Delta) \varphi 9$ & HR T18 & \\
\hline .1 .94 & $(/ .1 \cdot / 0)^{4}$ & $(\% \cdot / r T) r \Lambda$ & HR T13 & \\
\hline 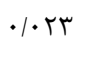 & $(/ / . / 9 \Lambda))$ & $(/ T / T V)$ TVT & HR T21 & Quad** \\
\hline.$/ \cdot 14$ & $(1.9 / r \Delta))$ & $(\% \cdot / 1 \Gamma) 19$ & HR T18 & \\
\hline.$/ \cdot r$ & $(/ . I / N Q) T r$ & $(/ .1 \cdot / \Delta) 1 r \Delta q$ & ${ }_{\mathrm{T} 21} \mathbf{H R}^{\mathbf{4 4 4}}$ & FTS \\
\hline$\cdot|\cdot r|$ & $\left(/ T / F^{\prime} T\right) V$ & $(/ F / F \psi(Y) \curlyvee \wedge q$ & HR T18 & \\
\hline $.1 \cdot Y F$ & $(/ / \Psi / 9 \Delta) \wedge$ & $(\% / / 1 \mu r) \Gamma / 9$ & HR T13 & \\
\hline •/. & $(/ / T / T \Lambda) 11$ & $(\% F / \cdot \varphi) F \wedge r$ & HR T21 & Quad \\
\hline .1 .19 & $(/ . \Delta / \cdot \Lambda) r$ & $(/ \cdot / 4 q) \Delta q$ & HR T18 & \\
\hline .1 .99 & $(/ .1 / T \cdot) V T$ & $(/ . \Delta \cdot / \mu) 9 \cdot 14$ & & سن بالاى al \\
\hline
\end{tabular}

**** Low Risk؛ *** High Risk :** Second Trimester Screening:* First Trimester Screening

\begin{tabular}{|c|c|c|c|c|c|c|c|c|c|}
\hline \multirow{3}{*}{ شيوع } & \multirow{3}{*}{$\mathrm{PPV}^{* * *}$} & \multirow{3}{*}{ 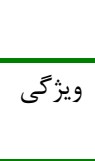 } & \multirow{3}{*}{$\mathrm{DR}^{* *}$} & & \multicolumn{5}{|c|}{ جدول r. مشخصات كار آيى تشخيصى تست NIPT در انواع تريزومى ها } \\
\hline & & & & منفى & مثبت & FPR $^{*}$ & ن اسكرين & 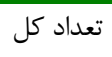 & نوع يروتكل \\
\hline & & & & 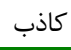 & حقيقى & & مثبت & 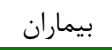 & \\
\hline $1: 111$ & $\% 9 r / \Delta$ & ११/१४ & $99 /$. & 1 & $1 .$. & $V(\% \cdot / \cdot \Delta q)$ & $(\% \cdot / \wedge 9) \mid \cdot \vee$ & 1199. & NIPT (T21) \\
\hline 1:NAF & $\% 9 \Lambda / F$ & ११/१८ & $9 r / 9$ & 1 & ir & $(\% \cdot / \cdot \Delta) 9$ & $(\% \cdot / 19) 19$ & 1199. & NIPT (T18) \\
\hline $1: 1 \cdot 1 \mathrm{~V}$ & $\%$ VN/9 & १९/৭४ & $1 \cdots$ & . & 11 & $(\% \cdot / \cdot r \Delta) r$ & $(\% \cdot / \mid r) \mid f$ & 1199. & NIPT (T13) \\
\hline & & & & & & $19(\% \cdot / 1 r 4)$ & $(\% / / V \vee) \mid r \Lambda$ & 1199. & Total \\
\hline
\end{tabular}

\footnotetext{
خط مشى و اساس تست NIPT انجام شده براى بررسى اختلالات

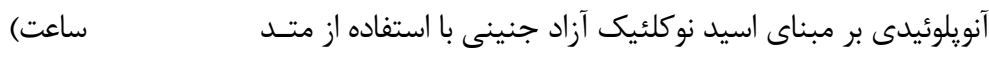

(Semiconductor Sequencing Platform) SSP

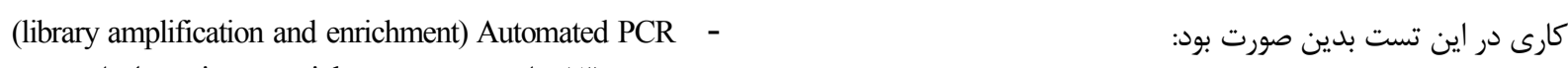
(حدود با ساعت و به صورت running overnight انجام شد). 1- روز اول: r- روز دوم:
} 


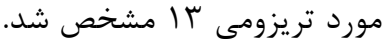

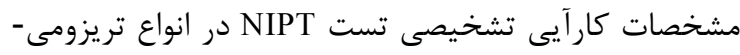
ها و ريسك اختلالات كروموزومهاى آس، جدول r نشان داده شده است. يك مورد سندرم داون به

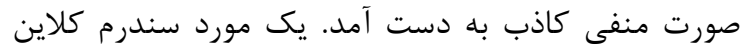
فلتر هم به دست آمد كه نتيجه سونوى بيمار يسر بود و

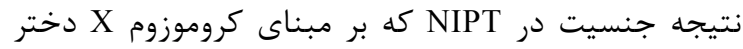
به دست آمد (يعنى دو كروموزوم X وجود دارد) و بر مبناى كروموزوم Y پر در آمد، كه نتيجه آمنيوسنتز كلاين فلتر

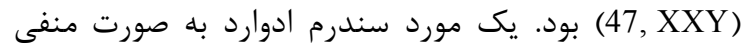

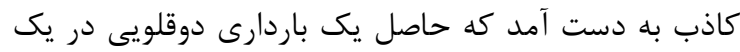

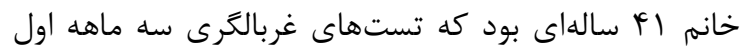
مشكلى از نظر سونوكرافى نداشت ولى در آنومالى اسكن

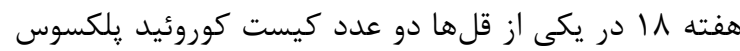

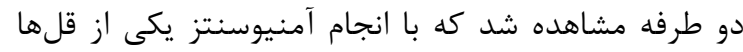

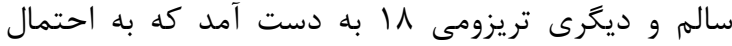

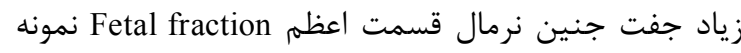

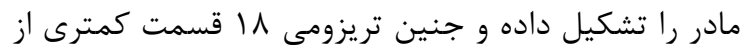

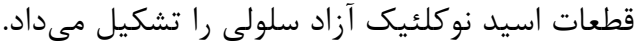

\section{بحث}

به طوركلى، ويزگَى تشخيصى NIPT در اين مطالعه و بر روى نزاد و زنتيك ايرانى جهت تشخيص تريزومى |r|r

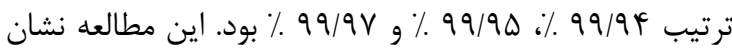
داد كه ارزش تست فوق در گروه يرخطر بيشتر از خروه كم

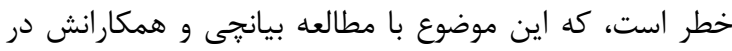

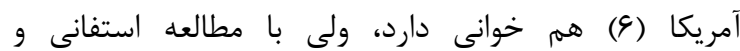
همكارانش (V) و مطالعه سانَ و همكار انش در آمريكا (N) كه

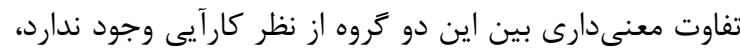

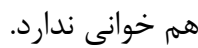

(حدود ه ساعت) Library DNA sequencing Automated data analysis بنابراين يروسه كارى اين تست حسدود هـ سـاعت و مــدت زماعـان

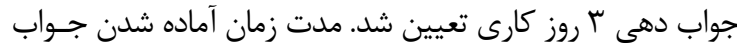

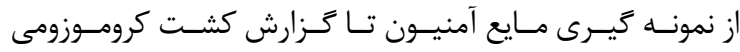

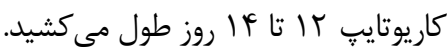

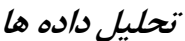

دادهاى يرسشنامهها در نرم افزار SPSS نسخه إ وارد شدند و بـا

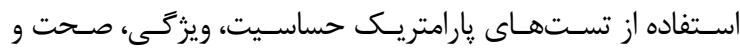
ارزشهاى اخبارى برآورد شد. ميزان معنى دارى با در نظـر كـرفتن

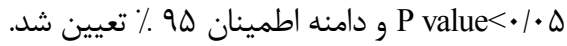

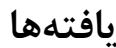
در كل . 119 نفر از زنان باردار كانديد آمنيوسنتز و NIPT

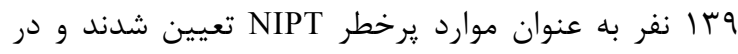

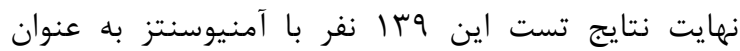
استاندارد تشخيصى طلايى مقايسه شد. ميانگين (土 انحراف

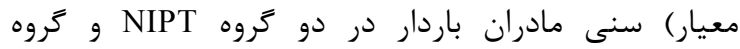

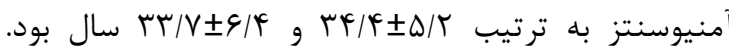

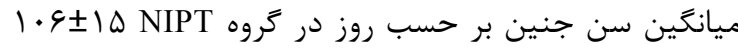

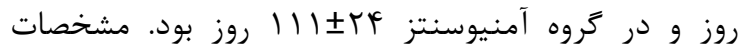

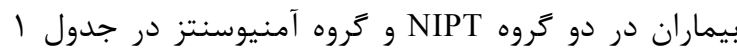

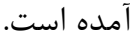
علتهاى مختلف ارجاع بيماران براى انجام تست NIPT در أمد است

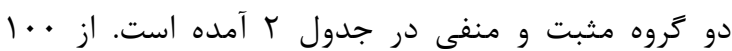

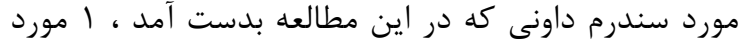

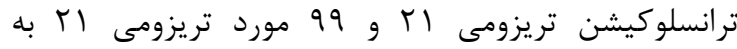
دست آمد. || مورد تريزومى سا آدر اين مطالعه مشاهده

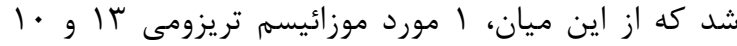

جدول F. مقايسه مشخصات كارآيى آناليتيك تست NIPT با ساير مطالعات

\begin{tabular}{|c|c|c|c|c|c|c|c|c|}
\hline \multicolumn{2}{|c|}{ Trisomy 13} & \multicolumn{2}{|c|}{ Trisomy 18} & \multicolumn{2}{|c|}{ Trisomy 21} & \multirow{2}{*}{ تعداد نمونه } & \multirow{2}{*}{ 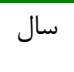 } & \multirow{2}{*}{ ن ام مطالعه } \\
\hline FPR & DR & FPR & DR & FPR & DR & & & \\
\hline$\% \cdot / \cdot 1 \mathrm{~V}$ & $\% 1 \ldots$ & $\% \cdot / \cdot \Delta$ & $\% 9 r / 9$ & $\% \cdot 1 \cdot 09$ & $\%$ ११/. & 1199. & $r \cdot I V$ & مطالعه حاضر \\
\hline$\% \cdot / 10$ & $\% 1 \ldots$ & $\% \cdot 110$ & $\% \wedge$. & $\% \cdot / 1 \Delta$ & $\% 1 \ldots$ & TTYT & $r . I V$ & Flock, et al ${ }^{12}$ \\
\hline- & - & - & - & $\% \cdot 119$ & $\% 9 \vee / T$ & $r F \Lambda$. & $r \cdot I V$ & Jiang, et al ${ }^{13}$ \\
\hline$\% \cdot$ & $\% 1 \ldots$ & $\% \cdot$ & $\% 1 \ldots$ & $\% \cdot / \pi$ & $\% 1 \ldots$ & frv & $r \cdot 19$ & Papageorghiou, et al ${ }^{14}$ \\
\hline$\% \cdot / 1 \pi$ & $\% 91 /$. & $\% \cdot / 14$ & $\%$ १९/ & $\% \cdot 1 \cdot 9$ & $\%$ ११/ & T مطالعه & $r \cdot 10$ & Gill MM, et al ${ }^{15}$ \\
\hline$\%$ & $\% 1 \ldots$ & $\% \cdot / v q$ & $\% 1 \ldots$ & $\% \cdot / \Delta T$ & $\%$ ११/१४ & TTVD & $r .1 F$ & Liao, et al ${ }^{16}$ \\
\hline
\end{tabular}


مطالعات ارزش تشخيصى NIPT در دوقلويى را كمتر از باردارى تك قلويى مىدانند و از طرف ديگر با وجودى كه

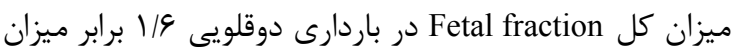
آن در باردارى تك قلويى است ولى ميانگين Fetal fraction در باردارى دوقلويى كمتر از تك قلويى است، در نتيجه به طور

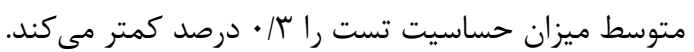
همان طور كه در جدول f مشاهده مىشود، بيشترين حجم نمونه مورد مطالعه مربوط به مطالعه حاضر است و DR مطالعه

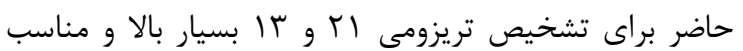
است و از مطالعه Jiang بالاتر است. همجنين FPR در مطالعه

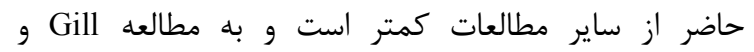

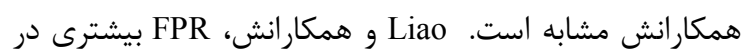
مرور مطالعات مشابه گزارش كردهاند.

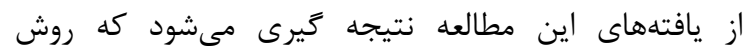

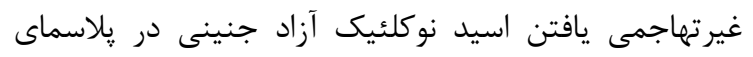
مادرى در زنتيك زنان ايرانى داراى حساسيت و اختصاصيت بالايى جهت تشخيص آنويلوئيدى است.

\section{تشكر و قدردانى}

اين مقاله حاصل پايان نامه رشته يزشكى جهت كسب درجه

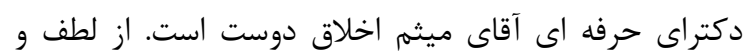

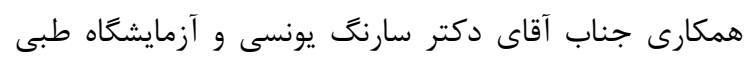
نيلو جهت همكارى در انجام اين طرح تحقيقاتى تقدير و تشكر

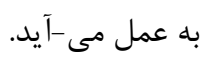

اين مطالعه يكى از اولين مطالعات در مقياس بزرگ براى بررسى اختلالات آنويلوئيدى بر مبناى اسيد نوكلئيك آزاد

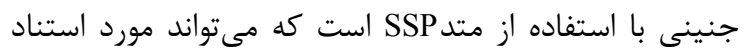

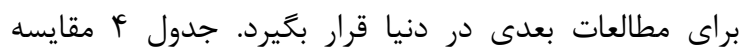

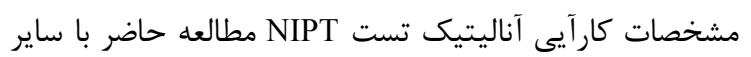
مطالعات را نشان مى مهدد.

نسبت يسر به دختر در سندرم داون در مطالعه حاضر بـ/ I

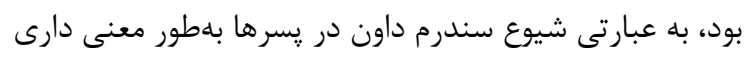

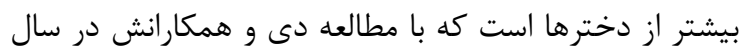

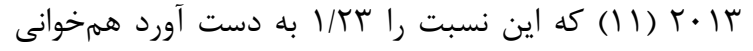
دارد و به احتمال زياد به علت نقص در جداشدن و يا تفكيك آن كروموزومى ميتوزى طى فرآيند اسيرماتوزنزيز است (11) درهنغام اسيرماتوزنز، به دليل تفاوت سايز محسوس بئ بين

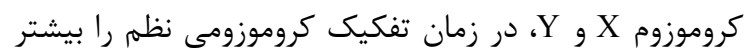
به هم مىزنند و تفكيك كروموزومى را به نفع تريزومى تغيير مىدهند (Y|-1|(1). اين مطالعه همجزنين نشان داد كه ريشه

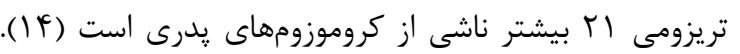

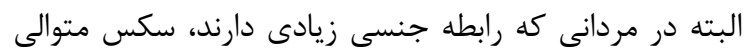

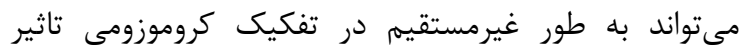
مضرى داشته باشد و همين طور در مردان معتاد هم تفكيك

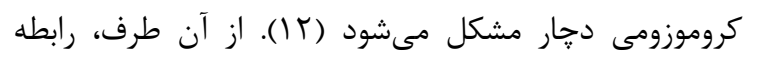

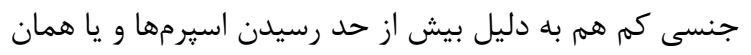

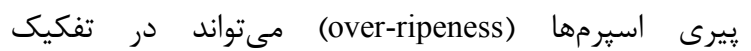

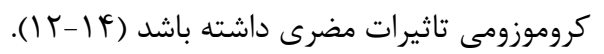

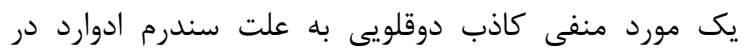

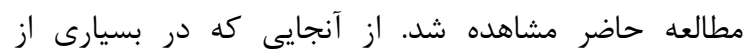

\section{REFERENCES}

1. Mc Sweeney LC, Monteith C, Kelliher N, Cody F, Tully EC, Dicker P, et al. Changing patterns of invasive fetal diagnostic testing in the era of NIPT. Am J Obstet Gynecol 2018;218:S162-3.

2. Hartwig TS, Ambye L, Sørensen S, Jørgensen FS. Discordant non-invasive prenatal testing (NIPT)-a systematic review. Prenat Diagn 2017;37:527-39.

3. Sikkema-Raddatz B, Johansson LF, De Boer EN, Boon EM, Suijkerbuijk RF, Bouman K, et al. an online tool for clinical interpretation of non-invasive prenatal testing (NIPT) results. Sci Rep 2016;6:38359.

4. Norton ME, Jacobsson B, Swamy GK, Laurent LC, Ranzini AC, Brar H, et al. Cell-free DNA analysis for noninvasive examination of trisomy. New Eng J Med 2015;372:1589-97.

5. American College of Obstetricians and Gynecologists. Committee Opinion: Cell-free DNA screening for fetal aneuploidy. Sci Rep 2015. 640:1-6.

6. Bianchi DW, Wilkins-Haug L. Integration of noninvasive DNA testing for aneuploidy into prenatal care: what has happened since the rubber met the road? Clin Chem 2014;60:78-87.

7. Stephanie CY, Chan KA, Zheng YW, Jiang P, Liao GJ, Sun H, et al. Size-based molecular diagnostics using plasma DNA for noninvasive prenatal testing. Proc Natl Acad Sci U S A 2014;111:8583-8.

8. Song K, Musci TJ, Caughey AB. Clinical utility and cost of non-invasive prenatal testing with cfDNA analysis in high-risk women based on a US population. J Matern Fetal Neonatal Med 2013;26:1180-5. 
9. Wald NJ, Lau KW, Bestwick JP, Old RW, Huttly WJ, Cheng R. Specifying a Gold Standard for the Validation of Fetal Fraction Estimation in Prenatal Screening. Clin Chem 2018;64:1394-9.

10. Oepkes D, Page-Christiaens GC, Bax CJ, Bekker MN, Bilardo CM, Boon EM, et al. Trial by Dutch laboratories for evaluation of non-invasive prenatal testing. Part I-clinical impact. Prenat Diagn 2016;36:1083-90.

11. Dey M, Sharma S, Aggarwal S. Prenatal screening methods for aneuploidies. North Am J Med Sci 2013;5:182.

12. Flöck A, Tu NC, Rüland A, Holzgreve W, Gembruch U, Geipel A. Non-invasive prenatal testing (NIPT): Europe's first multicenter post-market clinical follow-up study validating the quality in clinical routine. Arch Gynecol Obstet 2017;296:923-8.

13. Jiang T, Ding J, Zhang XQ, Zhang XJ, Zhang B, Wang T, et al. Analysis of Down syndrome failed to be diagnosed after prenatal screening: A multicenter study. Medicine 2017;96.

14. Papageorghiou AT, Khalil A, Forman M, Hulme R, Mazey R, Mousa HA, et al. Clinical evaluation of the IONA test: a non-invasive prenatal screening test for trisomies 21, 18 and 13. Ultrasound Obstet Gynecol 2016;47:188-93.

15. Gil MM, Quezada MS, Bregant B, Ferraro M, Nicolaides KH. Implementation of maternal blood cell-free DNA testing in early screening for aneuploidies. Ultrasound Obstet Gynecol 2013;42:34-40.

16. Liao GJ, Gronowski AM, Zhao Z. Non-invasive prenatal testing using cell-free fetal DNA in maternal circulation. Clinica Chimica Acta 2014 ;428:44-50. 